\title{
Effect of Replacing Alkyl Side Chains with Triethylene Glycols on Photovoltaic Properties of Easily Accessible Fluorene-Based Non- Fullerene Molecular Acceptors: Improve or Deteriorate?
}

\author{
Shoujie Zhang, ${ }^{\dagger}$ Jianhong Gao, ${ }^{\dagger}$ Wei Wang, ${ }^{\dagger}$ Chun Zhan, ${ }^{\dagger}$ Shengqiang Xiao, ${ }^{*}{ }^{\dagger}$ Z Zhiqiang Shi, \\ and Wei You* ${ }^{*},, \xi_{0}$
}

${ }^{\dagger}$ State Key Laboratory of Advanced Technology for Materials Synthesis and Processing, Wuhan University of Technology, Wuhan
430070, P. R. China

${ }^{\ddagger}$ College of Chemistry, Chemical Engineering and Materials Science; Collaborative Innovation Center of Functionalized Probes for Chemical Imaging in Universities of Shandong; Key Laboratory of Molecular and Nano Probes, Ministry of Education, Shandong Normal University, Jinan 250014, P. R. China

${ }^{\S}$ Department of Chemistry, University of North Carolina at Chapel Hill, Chapel Hill, North Carolina 27599-3290, United States

\begin{abstract}
Hydrophilic oligo(ethylene glycol) (OEG) side chains are more flexible than alkyl chains and can facilitate the $\pi-\pi$ stacking of conjugated polymer backbones, which has been proven to be a key structural feature leading to better device performance in polymer:fullerene blend polymer solar cells (PSCs). So far, little has been known about the influence of OEG side chains on the performance of non-fullerene acceptors in polymer:non-fullerene acceptor blends. Based on an easily accessible conjugated backbone of dicyanomethylene indanone-thiophene-fluorene-thiophene-dicyanometnylene indanone (DICTF), two non-fullerene molecular acceptors were synthesized with decyl (DICTF-C10) and triethylene glycol monoether (DICTF-TEG) side chains to blend with the polymer donor of PTB7-Th for PSCs. Replacing the decyl side chains with the

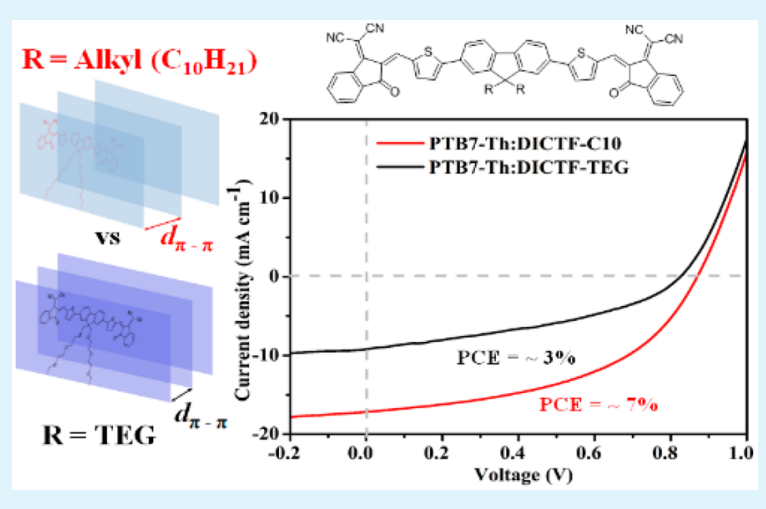
TEGs on DICTF does improve the $\pi-\pi$ stacking between the conjugated backbones as expected. For DICTF-TEG, nevertheless, forming the BHJ blend with the PTB7-Th donor leads to unfavorable film morphology structure of the active blend and deteriorated device performance with much lower PCE of 3.09\% compared to the blend of PTB7-Th:DICTF-C10 with the maximum PCE of $6.93 \%$ at optimized conditions. It is found that charge generation, transport, and recombination within the PSC devices of the two acceptors were greatly impacted by introducing TEG side chains instead of alkyls into the conjugated backbone of DICTF. This comparative study on understanding the side chain effect on device performance allows the establishment of guidance on molecular engineering of non-fullerene molecular acceptors to obtain high performance PSCs.
\end{abstract}

KEYWORDS: polymer solar cells, bulk heterojunction, non-fullerene molecular acceptor, side chain engineering, morphology

\section{INTRODUCTION}

With attractive potentials of low cost, lightweight, and flexibility, polymer solar cells (PSCs) have triggered tremendous research enthusiasm as one of environmentally friendly technologies to produce electricity from sunlight. ${ }^{1-4} \mathrm{Up}$ to now, efficient PSCs have generally consisted of an active layer with a blend of a p-type polymer and an n-type organic semiconductor in bulk heterojunction $(\mathrm{BHJ}) .{ }^{5}$ Accompanied by the onerous development of highly performing p-type polymers, fullerenes as well as polymeric and molecular electron acceptors have been attempted and employed as the mainstream n-type semiconductors for PSCs. ${ }^{6-10}$ Noteworthy, the emerging ladder-type molecular acceptors with dicyanomethylene indanone subunits, so-called as non-fullerene molecular acceptors, have shown overwhelming improvement recently on device performance over the other two types due to their easily tunable optoelectronic properties by chemical modifications. $^{11-14}$ In particular, the synergetic efforts on optimization at materials and devices have led to a record power conversion efficiency (PCE) up to $12 \%$ for polymer:fullerene blend, $9 \%$ for all-polymer blend, and $13 \%$ for polymer:non-fullerene small molecular acceptor blend PSCs in a single junction. ${ }^{15-19}$ Very recently, the maximum PCE value of PSCs were even pushed forward to $\sim 14 \%$ by the

Received: January 3, 2018

Accepted: February 21, 2018

Published: February 21, 2018 
combination of a non-fullerene acceptor with the fullerene acceptor of $\mathrm{PC}_{71} \mathrm{BM}$ in a ternary single $\mathrm{BHJ}$ PSC as reported by Ding et al. ${ }^{20}$

It has been well established that the excitonic working mechanism of a BHJ PSC makes each step contributing to convert light to electricity not only strongly correlated to the energy states of the materials employed but also to the morphological structures of the BHJ blends. ${ }^{21,22}$ It is critical for the production of highly efficient PSCs combining active donor and acceptor materials in a way that both energetically and morphologically facilitates exciton generation, dissociation, charge transport, and collection. Tremendous efforts on molecular engineering of active donor and acceptor materials on $\pi$-conjugated backbones have therefore been dedicated to fundamentally understand the correlation between the chemical structure, electronic structure, and morphological structure in conjugation with the device performance. ${ }^{22-29}$ As the structural variable beyond $\pi$-conjugated backbones, side chain engineering of active materials and resulted substantial impacts on electronic properties, morphology evolution, and device performance have been intensively investigated and revealed as well, such as the category, shape, length, branching point, and position of side chains linked to the conjugated backbones. $^{30-32}$ So far, alkyl chains have been the most widely used side chains in active materials for PSC application due to their strong ability of solubilization and controlling the selfassembly and optoelectronic properties in the solid state. Given the fact that the energy barrier of the rotation of $\mathrm{O}-\mathrm{CH}_{2}$ bonds in an oligo(ethylene glycol) (OEG) chain $(E=0.08 \mathrm{eV})$ is smaller than that of $\mathrm{CH}_{2}-\mathrm{CH}_{2}$ bonds in an alkyl chain $(E=$ $0.11 \mathrm{eV}){ }^{33}$ hydrophilic OEG chains have also attracted increasing attention and been employed instead of hydrophobic alkyl ones because of their less steric effect and more flexibility. ${ }^{30,31,24,34,35}$ For example, an amphiphilic polymeric donor of PBDTTT-TEG was developed by Hou et al. with the processability in polar non-halogenated solvents such as NMP, resulting a comparative device performance with that of the alkylated analogue in polymer:fullerene blend PSCs. ${ }^{36}$ Recently, Wang et al. demonstrated that the $\pi-\pi$ stacking distance of the polymer backbone decreased $0.3 \AA$ by introducing OEG chains into the polymer backbone of poly[2,7-fluorene-alt-5,5-(4,7-di2-thienyl-2,1,3-benzothiadiazole)], and the polymers exhibited higher hole mobility, red-shifted absorption in thin film, and smaller bandgap than those with the alkyl side chains. ${ }^{37}$ The enhancement of device performance was also observed in their later research by replacing branched alkyl chains with branched OEG chains in diketopyrrolopyrrole-based polymer donors in polymer:fullerene PSCs. ${ }^{38}$ The contribution of OEG side chains on improving device performance from these work was mainly ascribed to facilitating the $\pi-\pi$ stacking of conjugated polymer backbones, suggesting the potential of OEG chains as promising alternative to widely used alkyl side chains for active materials in PSC.

These early works motivate us to design non-fullerene molecular acceptors with OEG side chains since non-fullerene acceptors have been playing an increasing important role for PSCs. It is need to be noted that device performance improvements favored by OEG side chains instead of alkyl ones so far were mostly observed in polymer donors due to enhanced solid state organization of conjugated polymer backbones in polymer:fullerene blends. Nevertheless, little is known about the influence of OEG side chains on the performance of non-fullerene acceptors in polymer:non-full- erene acceptor blend PSCs. We envision that OEG side chains could also endow non-fullerene acceptors with improved $\pi-\pi$ stacking between conjugated backbones, which could also lead to better device performance as mentioned above. In order to disclose the effect of OEG side chains in non-fullerene molecular acceptors on its photovoltaic properties, herein, we select an easily accessible conjugated backbone of dicyanomethylene indanone-thiophene-fluorene-thiophene-dicyanometnylene indanone (DICTF) as the structural platform for non-fullerene molecular acceptors with alkyl (decyl, C10) and triethylene glycol monoether (TEG) side chains, respectively. The investigation on the optoelectronic property, solid state structure, and solar cell device performance of DICTF with alkyl (DICTF-C10) and TEG (DICTF-TEG) side chains was carried out in detail. Indeed, replacing the decyl chains with the TEG chains in the DICTF backbone improved the $\pi-\pi$ stacking of DICTF backbone. However, when PTB7Th was utilized as the polymer donor to blend with the acceptor of DICTF-C10 and DICTF-TEG for polymer:nonfullerene acceptor blend PSC devices respectively, a maximum PCE of $6.93 \%$ was obtained for the PTB7-Th:DICTF-C10 blend while it was only 3.09\% unexpectedly for the PTB7Th:DICTF-TEG blend at optimized conditions. The impact of introducing alkyl and TEG side chains into the conjugated backbone of DICTF on charge generation, transport, and recombination within the PSC devices of the two acceptors was clarified in conjugation with the morphology structure of the blend films.

\section{EXPERIMENTAL SECTION}

2.1. Measurements and Instruments. General experimental information on materials, device fabrication, and characterizations can be found in the Supporting Information.

2.2. Synthesis of Compounds. 2,7-Dibromo-9.9-Didecylfluorene. To a flask containing $50 \mathrm{~mL}$ of DMSO was added 2,7dibromofluorene $(3.24 \mathrm{~g}, 10.0 \mathrm{mmol})$, tetra- $n$-butylammonium iodide $(1.11 \mathrm{~g}, 3.0 \mathrm{mmol}), 1$-bromodecane $(5.30 \mathrm{~g}, 24.0 \mathrm{mmol})$, and $15 \mathrm{~mL}$ of $50 \% \mathrm{NaOH}$ solution under nitrogen. After stirring for $12 \mathrm{~h}$ at 100 ${ }^{\circ} \mathrm{C}$, the mixture was then poured into $50 \mathrm{~mL}$ of water and extracted with petroleum ether. The organic layer was washed with water and dried over anhydrous $\mathrm{Na}_{2} \mathrm{SO}_{4}$. The solvent was removed under reduced pressure, and the residue was purified by silica gel chromatography using petroleum ether as the eluent to produce $5.70 \mathrm{~g}$ of the target compound (yield, 95\%). ${ }^{1} \mathrm{H}$ NMR $(500 \mathrm{MHz}$, $\left.\mathrm{CDCl}_{3}\right), \delta(\mathrm{ppm}): 7.52(d, J=7.10 \mathrm{~Hz}, 2 \mathrm{H}), 7.53(m, 4 \mathrm{H}), 1.91(m$, $4 \mathrm{H}), 1.28-1.08(m, 30 \mathrm{H}), 0.87(t, 6 \mathrm{H}), 0.59(m, 4 \mathrm{H}) .{ }^{13} \mathrm{C}$ NMR $(125$ $\left.\mathrm{MHz}, \mathrm{CDCl}_{3}\right), \delta(\mathrm{ppm}): 152.57,139.07,130.16,126.20,121.48$, $121.10,55.70,40.15,31.87,29.87,29.50,29.27,29.20,23.65,22.66$, 14.09.

2,7-Bis(2-thienyl)-9,9'-didecylfluorene. 2,7-Dibromo-9.9-didecylfluorene $(2.42 \mathrm{~g}$, $4.0 \mathrm{mmol})$, tributyl(thiophen-2-yl)stannane (4.45 g, $11.93 \mathrm{mmol})$, and $\mathrm{Pd}\left(\mathrm{PPh}_{3}\right)_{4}(50 \mathrm{mg}, 0.043 \mathrm{mmol}, 1 \%$ equiv $)$ was added into $50 \mathrm{~mL}$ of anhydrous toluene under nitrogen. After being stirred at reflux for $12 \mathrm{~h}$, the mixture was cooled down to room temperature and poured into $50 \mathrm{~mL}$ of water. The crude mixture from subsequent chloroform extractions was purified via silica gel chromatography using petroleum ether as the eluent to produce $2.07 \mathrm{~g}$ of the target compound (yield, 85\%). ${ }^{1} \mathrm{H}$ NMR $(500 \mathrm{MHz}$, $\left.\mathrm{CDCl}_{3}\right), \delta(\mathrm{ppm}): 7.67(d, J=7.40 \mathrm{~Hz}, 2 \mathrm{H}), 7.60(d, J=7.75 \mathrm{~Hz}, 2 \mathrm{H})$, $7.56(\mathrm{~s}, 2 \mathrm{H}), 7.37(\mathrm{~s}, 2 \mathrm{H}), 7.27(\mathrm{~s}, 2 \mathrm{H}), 7.09(d, J=2.75 \mathrm{~Hz}, 2 \mathrm{H}), 2.01$ $(m, 4 \mathrm{H}), 1.27-1.05(m, 30 \mathrm{H}), 0.83(t, J=6.30 \mathrm{~Hz}, 6 \mathrm{H}), 0.69(m, 4 \mathrm{H})$. ${ }^{13} \mathrm{C}$ NMR (125 MHz, $\left.\mathrm{CDCl}_{3}\right), \delta$ (ppm): 151.73, 145.19, 140.24, $133.31,128.05,125.00,124.51,122.89,120.20,120.09,55.32,40.41$, $31.88,29.99,29.54,29.28,29.22,23.78,22.66,14.10$. MALDI-TOF MS for $\mathrm{C}_{41} \mathrm{H}_{54} \mathrm{~S}_{2}$ : calcd 610.3667; found $610.3660\left(\mathrm{M}^{+}\right)$. 
Scheme 1. Synthetic Route of DICTF-C10 and DICTF-TEG
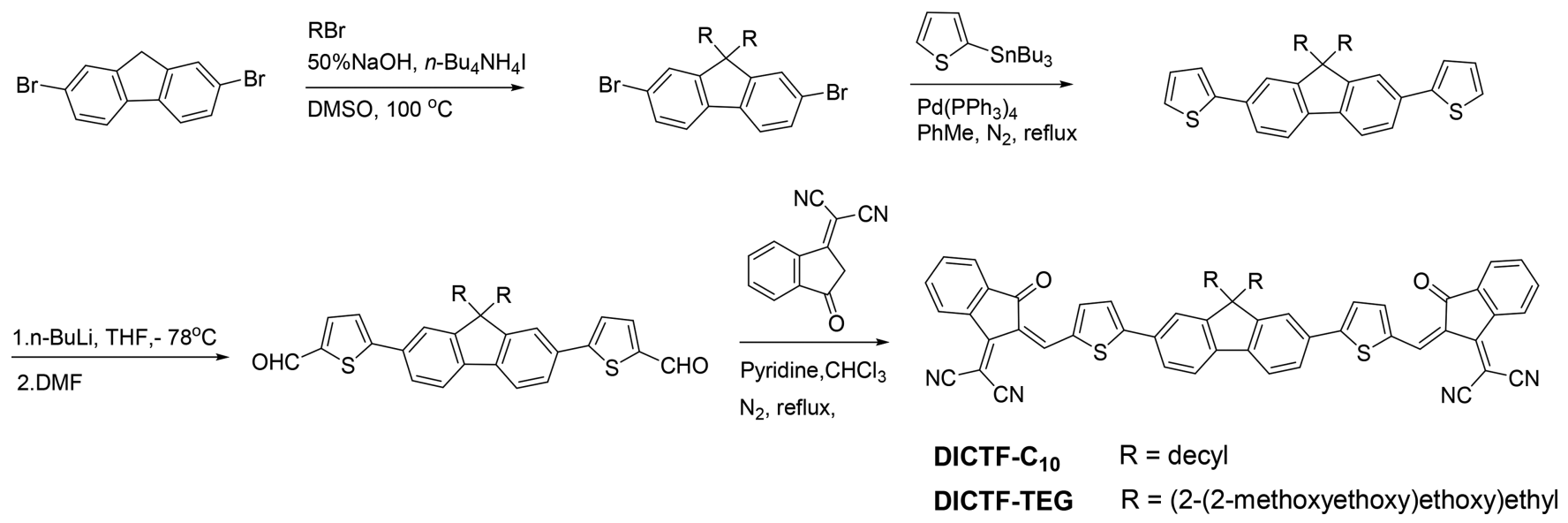

5,5'-(9,9-Didecylfluorene-2,7-diyl)bis(thiophene-2-carbaldehyde). 2,7-Bis(2-thienyl)-9,9'-didecylfluorene $(1.22 \mathrm{~g}, 2.0 \mathrm{mmol})$ was added into a dry flask containing $50 \mathrm{~mL}$ of anhydrous THF under $\mathrm{N}_{2}$. After the reaction mixture was cooled to $-78^{\circ} \mathrm{C}$, a $2.5 \mathrm{M}$ solution of $n$-BuLi in hexane $(2.1 \mathrm{~mL}, 5.5 \mathrm{mmol})$ was added dropwise and stirred for $1 \mathrm{~h}$ before $0.5 \mathrm{~mL}$ of dry DMF was added. Five minutes later, the reaction was quenched with water and extracted with chloroform. The organic layer was washed with water and dried over anhydrous $\mathrm{Na}_{2} \mathrm{SO}_{4}$. After rotary evaporation, the mixture was purified via silica gel column chromatography eluted by petroleum ether/ethyl acetate $(5: 1, \mathrm{v} / \mathrm{v})$ to afford $0.93 \mathrm{~g}$ of the pure product as a yellow solid (yield, $70 \%$ ). ${ }^{1} \mathrm{H}$ NMR $\left(500 \mathrm{MHz}, \mathrm{CDCl}_{3}\right), \delta(\mathrm{ppm}): 9.91(\mathrm{~s}, 2 \mathrm{H}), 7.77(\mathrm{~s}, 2 \mathrm{H})$, $7.75(d, J=7.30 \mathrm{~Hz}, 2 \mathrm{H}), 7.70(d, J=7.30 \mathrm{~Hz}, 2 \mathrm{H}), 7.64(s, 2 \mathrm{H}), 7.49$ $(s, 2 \mathrm{H}), 2.03(m, 4 \mathrm{H}), 1.28-1.04(m, 30 \mathrm{H}), 0.83(t, J=5.55 \mathrm{~Hz}, 6 \mathrm{H})$, $0.68(m, 4 \mathrm{H}) .{ }^{13} \mathrm{C} \mathrm{NMR}\left(125 \mathrm{MHz}, \mathrm{CDCl}_{3}\right), \delta(\mathrm{ppm}): 182.65,154.77$, $152.27,142.27,141.64,137.37,132.43,125.73,124.04,120.77,120.71$, 55.57, 40.20, 31.83, 29.86, 29.48, 29.24, 29.15, 23.77, 22.62, 14.07 . MALDI-TOF MS for $\mathrm{C}_{43} \mathrm{H}_{54} \mathrm{O}_{2} \mathrm{~S}_{2}$ : calcd 666.3536; found 666.3557 $\left(\mathrm{M}^{+}\right)$.

DICTF-C10. 5,5'-(9,9-Didecyl-9H-fluorene-2,7-diyl)bis(thiophene-2carbaldehyde) (0.33 g, $0.5 \mathrm{mmol})$ and 2-(3-oxo-2,3-dihydro- $1 \mathrm{H}$-inden1-ylidene)malononitrile $(0.29 \mathrm{~g}, 1.5 \mathrm{mmol})$ were dissolved in $100 \mathrm{~mL}$ of chloroform under the protection of nitrogen. $2 \mathrm{~mL}$ of pyridine was then added in, and the reactants were stirred at reflux for $12 \mathrm{~h}$. The reaction mixture was concentrated under reduced pressure, and the resultant was purified by silica gel chromatography using chloroform/ petroleum $(1: 1, \mathrm{v} / \mathrm{v})$ as the eluent. The crude product was then recrystallized from the mixed solvent of petroleum ether and chloroform to afford $380 \mathrm{mg}$ of pure DICTF-C10 as a dark blue solid (yield, 75\%). ${ }^{1} \mathrm{H}$ NMR $\left(500 \mathrm{MHz}, \mathrm{CDCl}_{3}\right), \delta(\mathrm{ppm}): 8.88(s, J=$ $1.60 \mathrm{~Hz}, 2 \mathrm{H}), 8.70(\mathrm{~s}, 2 \mathrm{H}), 7.96(\mathrm{~s}, 2 \mathrm{H}), 7.88(\mathrm{~s}, 2 \mathrm{H}), 7.83(\mathrm{~s}, 2 \mathrm{H})$, $7.78(\mathrm{~m}, 8 \mathrm{H}), 7.60(\mathrm{~s}, 2 \mathrm{H}), 2.13(\mathrm{~m}, 4 \mathrm{H}), 1.28-1.07(\mathrm{~m}, 30 \mathrm{H}), 0.78$ $(t, J=6.70 \mathrm{~Hz}, 6 \mathrm{H}), 0.69(m, 4 \mathrm{H}) .{ }^{13} \mathrm{C} \mathrm{NMR}\left(125 \mathrm{MHz}, \mathrm{CDCl}_{3}\right), \delta$ (ppm): 188.34, 160.81, 160.36, 152.58, 146.28, 142.34, 140.02, 137.98, $136.92,136.45,135.26,134.59,132.64,126.24,125.02,123.83,121.02$, $120.86,114.48,114.40,69.99,55.90,40.25,31.84,29.90,29.54,29.51$, 29.26, 23.87, 22.62, 14.06. MALDI-TOF MS for $\mathrm{C}_{69} \mathrm{H}_{66} \mathrm{~N}_{4} \mathrm{O}_{2} \mathrm{~S}_{2}$ : calcd 1018.4314; found 1018.4301 $\left(\mathrm{M}^{+}\right)$.

2,7-Dibromo-9,9-bis(2-(2-(2-methoxyethoxy)ethoxy)ethyl)fluorene. 2,7-Dibromofluorene (3.24 g, $10.0 \mathrm{mmol})$, tetra- $n$ butylammonium iodide $(1.11 \mathrm{~g}, 3.0 \mathrm{mmol}), 1$-bromo-2-(2-(2methoxyethoxy)ethoxy)ethane (5.45 g, $24.0 \mathrm{mmol})$, and $15 \mathrm{~mL}$ of $50 \% \mathrm{NaOH}$ solution were added into $50 \mathrm{~mL}$ of DMSO under nitrogen. After stirring for $12 \mathrm{~h}$ at $100{ }^{\circ} \mathrm{C}$, the mixture was then poured into $50 \mathrm{~mL}$ of water and extracted with petroleum ether. The organic layer was washed with water and dried over anhydrous $\mathrm{Na}_{2} \mathrm{SO}_{4}$. The solvent was removed under reduced pressure, and the residue was purified by silica gel chromatography using petroleum ether as the eluent to produce $3.69 \mathrm{~g}$ of the target compound (yield, $60 \%) .{ }^{1} \mathrm{H}$ NMR (500 MHz, $\left.\mathrm{CDCl}_{3}\right), \delta(\mathrm{ppm}): 7.53(\mathrm{~s}, 2 \mathrm{H}), 7.50(\mathrm{~m}$,
2H), $7.47(m, 2 \mathrm{H}), 3.50(d, 8 \mathrm{H}), 3.37(m, 4 \mathrm{H}), 3.34(s, 6 \mathrm{H}), 3.20(m$, $4 \mathrm{H}), 2.77(t, J=6.50 \mathrm{~Hz}, 4 \mathrm{H}), 2.33(t, J=5.85 \mathrm{~Hz}, 4 \mathrm{H}) .{ }^{13} \mathrm{C} \mathrm{NMR}$ $\left(125 \mathrm{MHz}, \mathrm{CDCl}_{3}\right), \delta$ (ppm): 150.96, 138.45, 130.65, 126.72, 121.63, $121.20,71.87,70.46,70.43,70.05,66.80,58.97,51.93,39.47$.

2,7-Bis(2-thienyl)-9,9'-bis(2-(2-(2-methoxyethoxy)ethoxy)ethyl)fluorene. 2,7-Dibromo-9,9-bis(2-(2-(2-methoxyethoxy)ethoxy)ethyl)fluorene $(2.49 \mathrm{~g}, 4.0 \mathrm{mmol})$, tributyl(thiophen-2-yl)stannane (11.93 mmol, $4.45 \mathrm{~g})$, and $\mathrm{Pd}\left(\mathrm{PPh}_{3}\right)_{4}(50 \mathrm{mg}, 0.043 \mathrm{mmol}$, $1 \%$ equiv) were added into $50 \mathrm{~mL}$ of anhydrous toluene under $\mathrm{N}_{2}$. The mixture was stirred under reflux for $12 \mathrm{~h}$. After being concentrated via rotary evaporation under reduced pressure, the mixture was purified via silica gel chromatography by using petroleum ether:ethyl acetate $(2: 1, \mathrm{v} / \mathrm{v})$ as the eluent to obtain $2.11 \mathrm{~g}$ of the target compound (yield, $85 \%) .{ }^{1} \mathrm{H}$ $\operatorname{NMR}\left(500 \mathrm{MHz}, \mathrm{CDCl}_{3}\right), \delta(\mathrm{ppm}): 7.67-7.61(m, 6 \mathrm{H}), 7.39(s, 2 \mathrm{H})$, $7.30(s, 2 \mathrm{H}), 7.11(s, 2 \mathrm{H}), 3.47-3.37(m, 12 \mathrm{H}), 3.29(\mathrm{~s}, 6 \mathrm{H}), 3.22(\mathrm{~m}$, $4 \mathrm{H}), 2.84(t, J=6.35 \mathrm{~Hz}, 4 \mathrm{H}), 2.45(t, J=6.20 \mathrm{~Hz}, 4 \mathrm{H}) .{ }^{13} \mathrm{C} \mathrm{NMR}$ $\left(125 \mathrm{MHz}, \mathrm{CDCl}_{3}\right), \delta$ (ppm): 149.96, 144.62, 139.45, 133.64, 132.15, 132.02, 132.00, 128.60, 12880. MALDI-TOF MS for $\mathrm{C}_{35} \mathrm{H}_{42} \mathrm{O}_{6} \mathrm{~S}_{2}$ : calcd 622.2423; found $622.2416\left(\mathrm{M}^{+}\right)$.

5,5'-(9,9-Bis(2-(2-(2-methoxyethoxy)ethoxy)ethyl)fluorene-2,7diyl)bis(thiophene-2-carbaldehyde). To a dry flask was added in 2,7bis(2-thienyl)-9,9'-bis(2-(2-(2-methoxyethoxy)ethoxy)ethyl)fluorene $(1.24 \mathrm{~g}, 2.0 \mathrm{mmol})$ and $50 \mathrm{~mL}$ of anhydrous THF under nitrogen protection. The mixture was then cooled down to $-78{ }^{\circ} \mathrm{C}$ and added in dropwise a $2.5 \mathrm{M}$ solution of $n$-BuLi in hexane $(2.1 \mathrm{~mL}, 5.5 \mathrm{mmol})$ under stirring. About $1 \mathrm{~h}$ later, $0.5 \mathrm{~mL}$ of dry DMF was added in and the mixture was kept at $-78{ }^{\circ} \mathrm{C}$ for another $5 \mathrm{~min}$ before $10 \mathrm{~mL}$ of water was added in one portion. The mixture was then extracted with chloroform. After being washed with water and dried over anhydrous $\mathrm{Na}_{2} \mathrm{SO}_{4}$, the organic was then concentrated via rotary evaporation. The crude product was then purified via silica gel column chromatography eluted by petroleum ether/ethyl acetate $(1: 1, \mathrm{v} / \mathrm{v})$ to give $0.95 \mathrm{~g}$ of the pure product as a yellow solid (yield, $70 \%) .{ }^{1} \mathrm{H}$ NMR (500 MHz, $\left.\mathrm{CDCl}_{3}\right), \delta(\mathrm{ppm}): 9.91(s, 2 \mathrm{H}), 7.78-7.69(m, 8 \mathrm{H})$, $7.50(s, 2 \mathrm{H}), 3.45-3.35(m, 12 \mathrm{H}), 3.28(s, 6 \mathrm{H}), 3.20(s, 4 \mathrm{H}), 2.85(t, J$ $=8.85 \mathrm{~Hz}, 4 \mathrm{H}), 2.46(t, J=6.05 \mathrm{~Hz}, 4 \mathrm{H}) .{ }^{13} \mathrm{C} \mathrm{NMR}(125 \mathrm{MHz}$, $\left.\mathrm{CDCl}_{3}\right), \delta(\mathrm{ppm}): 182.67,154.23,150.64,142.43,140.91,137.41$, 132.69, 126.20, 124.28, 121.09, 120.91, 71.82, 70.42, 70.06, 66.98, 58.93, 51.83, 39.62. MALDI-TOF MS for $\mathrm{C}_{37} \mathrm{H}_{42} \mathrm{O}_{8} \mathrm{~S}_{2}$, calcd 678.2321; found 678.2313 $\left(\mathrm{M}^{+}\right)$, $701.2210\left(\mathrm{M}+\mathrm{Na}^{+}\right)$.

DICTF-TEG. To a flask containing $100 \mathrm{~mL}$ of chloroform was added 5,5'-(9,9-bis(2-(2-(2-methoxyethoxy)ethoxy)ethyl)fluorene-2,7-diyl)bis(thiophene-2-carbaldehyde) (0.34 g, $0.5 \mathrm{mmol}), 2$-(3-oxo-2,3dihydro- $1 H$-inden-1-ylidene)malononitrile $(0.29 \mathrm{~g}, 1.5 \mathrm{mmol})$, and 2 $\mathrm{mL}$ of pyridine under the protection of nitrogen. The mixture was then stirred under reflux for $12 \mathrm{~h}$. After evaporating the solvent under reduced pressure, the crude product was purified by silica gel column chromatography by using chloroform as the eluent and subsequently recrystallized from the mixture solvent of petroleum ether and chloroform to afford $385.0 \mathrm{mg}$ of DICTF-TEG as a dark blue solid 
(yield, 75\%). ${ }^{1} \mathrm{H}$ NMR (500 MHz, $\left.\mathrm{CDCl}_{3}\right), \delta(\mathrm{ppm}): 8.89(s, 2 \mathrm{H})$, $8.70(d, J=7.05,2 \mathrm{H}), 7.96(d, J=5.80,2 \mathrm{H}), 7.90-7.78(m, 12 \mathrm{H})$, $7.61(s, 2 \mathrm{H}), 3.46-3.37(m, 12 \mathrm{H}), 3.27(s, 6 \mathrm{H}), 3.23(s, 4 \mathrm{H}), 2.89(t, J$ $=6.15 \mathrm{~Hz}, 4 \mathrm{H}), 2.54(t, J=6.05 \mathrm{~Hz}, 4 \mathrm{H}) .{ }^{13} \mathrm{C}$ NMR $(125 \mathrm{MHz}$, $\left.\mathrm{CDCl}_{3}\right), \delta(\mathrm{ppm}): 188.21,160.28,160.13,151.03,146.23,139.99$, 137.86, 136.91, 136.53, 135.28, 134.64, 132.83, 125.36, 125.14, 122.81, $121.33,121.16,114.46,114.36,71.82,70.42,70.12,70.08,67.04$, 58.93, 52.09, 39.61. MALDI-TOF MS for $\mathrm{C}_{61} \mathrm{H}_{50} \mathrm{~N}_{4} \mathrm{O}_{8} \mathrm{~S}_{2}$ : calcd 1030.3070; found $1053.2962\left(\mathrm{M}+\mathrm{Na}^{+}\right)$.

\section{RESULTS AND DISCUSSION}

3.1. Synthesis. The synthetic route for the target nonfullerene small molecular acceptors is depicted in Scheme 1 . DICTF was selected as the conjugated backbone of nonfullerene acceptors due to its easy accessibility and comparable photovoltaic performance with fullerene acceptors when blended with the polymer donor of PTB7-Th. ${ }^{39}$ The acceptors with decyl (C10) and 2-(2-(2-methoxyethoxy)ethoxy)ethyl (TEG) side chains at the 9,9-position of the central fluorene are denoted as DICTF-C10 and DICTF-TEG, respectively. The decyl chain was selected because the number of carbon atoms along the side chain is same with that of carbon and oxygen atoms along the TEG side chain, which is helpful to clarify the effect of both chains on molecular stacking. In addition, the thermal property investigated by thermogravimetric analysis (TGA) shows a $5 \%$ weight loss temperature higher than $300^{\circ} \mathrm{C}$ for both acceptors as indicated in Figure S1. Nevertheless, a slight tendency of easier thermal decomposition can be observed for DICTF-TEG.

3.2. Optical Properties and Energy Band Structures. The UV-vis absorption spectra of DICTF-C10 and DICTFTEG in dilute $o$-dichlorobenzene $(o$-DCB $)$ solution $\left(1 \times 10^{-5}\right.$ $\mathrm{M})$ at room temperature and in thin film are presented in Figure 1. In $o$-DCB solution, DICTF-C10 and DICTF-TEG

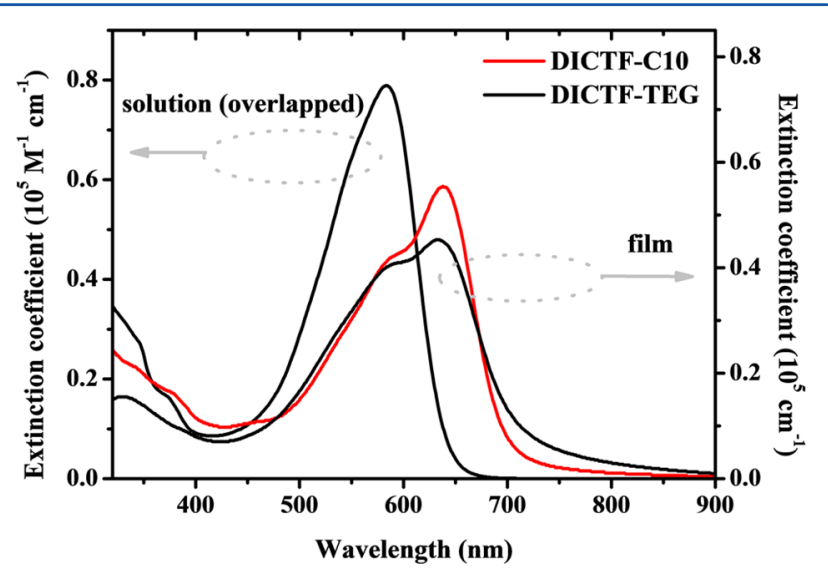

Figure 1. Absorption spectra of DICTF-C10 and DICTF-TEG in dilute $o$-dichlorobenzene solution at room temperature and in film.

exhibit identical absorption behaviors with an absorption peak at $\sim 585 \mathrm{~nm}$ corresponding to the $\pi-\pi^{*}$ transition of the conjugated backbone, indicative of the equal effect of the alkyl and TEG side chains on the electronic structure of the conjugated backbone in molecular level. In thin film as cast from the $o$-DCB solution for DICTF-C10, besides the maximum absorption at $\sim 585 \mathrm{~nm}$, an additional enhanced vibronic absorption peak emerges at $\sim 639 \mathrm{~nm}$ with the extinction coefficient of $0.56 \times 10^{5} \mathrm{~cm}^{-1}$ due to the interaction of the molecules in solid state. So does the DICTF-TEG thin film, with the appearance of the additional enhanced vibronic absorption maxima at $\sim 631 \mathrm{~nm}$ and the extinction coefficient of $0.46 \times 10^{5} \mathrm{~cm}^{-1}$. Moreover, a slightly narrower spectrum with relatively intensified peaks in the absorption range can be observed in the DICTF-C10 film compared with the DICTFTEG thin film.

The energy levels of frontier orbitals of the two acceptors were first determined by cyclic voltammetry as shown in Figure S2. Irreversible reductive and oxidative responses were observed for both acceptors. The HOMO energy level $(-5.67 \mathrm{eV})$ of DICTF-C10 was calculated from the oxidation onset potential $\left(0.97 \mathrm{~V}\right.$ vs $\left.\mathrm{Ag} / \mathrm{Ag}^{+}\right)$while it was found to locate at $-5.68 \mathrm{eV}$ for DICTF-TEG estimated from the oxidation onset potential $\left(0.98 \mathrm{~V} \mathrm{vs} \mathrm{Ag} / \mathrm{Ag}^{+}\right)$. The LUMO energy level of DICTF-C10 and DICTF-TEG was estimated to be -3.89 and $-3.92 \mathrm{eV}$, corresponding to the reduction onset potential of -0.81 and $-0.78 \mathrm{~V}$ versus $\mathrm{Ag} / \mathrm{Ag}^{+}$, respectively. Ultraviolet photoelectron spectroscopy (UPS) was also utilized to examine the energy band structures of the thin films of the two acceptors (Figure S3). The HOMO energy levels of the DICTF-C10 and DICTF-TEG thin films spin-coated on an ITO substrate were found to be at -5.65 and $-5.68 \mathrm{eV}$, respectively. Taking into account of the optical band gap $\left(E_{g}\right.$, $1.76 \mathrm{eV}$ ) derived from the absorption onset at $700 \mathrm{~nm}$ in the film of DICTF-C10, the LUMO energy level of DICTF-C10 was estimated to be at $-3.89 \mathrm{eV}$ according to the equation of $E_{\mathrm{LUMO}}=\left(E_{\text {HOMO }}+E_{\mathrm{g}, \mathrm{opt}}\right) \mathrm{eV}$. In the same way, the LUMO energy level of DICTF-TEG was found to be at $-3.94 \mathrm{eV}$ due to its absorption onset at $712 \mathrm{~nm}$ (corresponding to the $E_{\mathrm{g}}$ of $1.74 \mathrm{eV}$ ). The energy levels of frontier orbitals of the two acceptors obtained from the UPS measurement are very close to that from the $\mathrm{CV}$ results. On the other hand, the slightly higher LUMO value of DICTF-C10 could provide a higher open circuit voltage $\left(V_{\text {oc }}\right)$ when a given polymer donor is employed within a BHJ polymer solar cell.

3.3. Solid State Ordering. To gain insight into the structural ordering of the two acceptors in solid state, powdery $\mathrm{X}$-ray diffraction measurements were first carried out on pure molecules. As shown in Figure S4, DICTF-C10 shows a distinct diffraction peaks at $2 \theta$ of $5.60^{\circ}$ with a distance value of $15.78 \AA$ determined by the size of alkyl side chains. A diffraction peak at $2 \theta$ around $25.40^{\circ}$ can be observed as well, corresponding to a typical $\pi-\pi$ stacking distance of $3.50 \AA$ between the conjugated backbones. For DICTF-TEG powder, there is no distinct diffraction in the range from $3^{\circ}$ to $8^{\circ}$ where a lamellar diffraction resulted from TEG chains is supposed to appear, while a diffraction peak appears at $2 \theta$ of $26.24^{\circ}$ corresponding to a decreased $\pi-\pi$ stacking distance of $3.39 \AA$ between the conjugated backbones. Grazing incidence wide-angle X-ray scattering (GIWAXS) was further employed to straightforwardly investigate the neat film structures of the two acceptors. As shown in Figure 2, both pristine acceptor films show evident (010) reflections in the out-of-plane direction, indicating that most of the molecules take preferential face-on orientation on the substrate. The corresponding weak (100) peak in the inplane direction can only be detected at $q_{r}=0.28 \AA^{-1}$ corresponding to the interchain distance of $22.43 \AA$ for DICTF-C10. The important feature is that DICTF-C10 clearly shows the out-of-plane $(010)$ reflection at $q_{z}=1.77 \AA^{-1}$ corresponding to the $\pi-\pi$ stacking distance of $3.55 \AA^{-1}$ while DICTF-TEG shows the out-of-plane (010) reflection with much stronger intensity at $q_{z}=1.82 \AA^{-1}$ corresponding to a decreased $\pi-\pi$ stacking distance of $3.45 \AA^{-1}$, indicating improved $\pi-\pi$ stacking in film for DICTF-TEG in agreement 


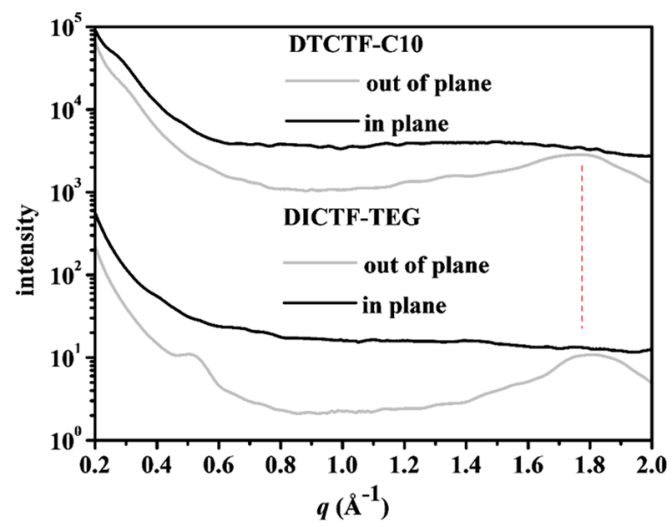

Figure 2. In-plane and out-of-plane GIWAXS profiles of the pristine films of DICTF-C10 and DICTF-TEG.

with the powdery XRD results. This clearly indicates that incorporating TEG chains instead of alkyl ones into conjugated backbones of DICTF does enhance molecule packing in the $\pi-\pi$ stacking direction due to their better flexibility, which is consistent with the results from the literature. ${ }^{37,38}$ It is worth noting that a (200) reflection at $q_{z}=0.50 \AA^{-1}$ can be observed as well although no corresponding (010) reflection can be apparently observed along the in-plane direction for DICTFTEG, indicating partial edge-on orientation of the crystals on the substrate. This is a somewhat surprising result of the solid state ordering features between DICTF-C10 and DICTF-TEG. Empirically, improved crystallinity or $\pi-\pi$ stacking of active materials within a $\mathrm{BHJ}$ film could lead to enhanced device performance. Such distinction on solid state ordering between the two acceptors sparked our strong curiosity on their photovoltaic performance due to the strong correlations that have been gained between the morphological structure and photovoltaic performance of active materials within a PSC device.

3.4. Photovoltaic Performance. Inverted BHJ polymer solar cell devices were fabricated by blending the acceptors and the electron donor of PTB7-Th onto a $\mathrm{ZnO}$-coated ITO electrode and then capping the devices with $8 \mathrm{~nm}$ of $\mathrm{MoO}_{3}$ followed by $100 \mathrm{~nm}$ of silver. The energy level diagram of the electronic materials within the device architecture is depicted in Figure S4, which clearly indicates the potential of energetically favorable electron transfer from the polymer donor of PTB7Th to DICTF-C10 and DICTF-TEG. The optimal PTB7Th:acceptor weight ratio was found to be $2: 3$ for both acceptors while the $\mathrm{BHJ}$ film thickness was optimized to be around 68 and $65 \mathrm{~nm}$ for the BHJ blend of PTB7-Th:DICTF-C10 and PTB7-Th:DICTF-TEG, respectively. The application of solvent additives such as 1,8-diiodooctane (DIO) and 1-chloronathphalene $(\mathrm{CN})$ in film processing was found to bring down the device performance. The current density-voltage $(J-V)$ curves of the optimized devices without any solvent additive acquired under simulated AM 1.5G sunlight illumination $(100 \mathrm{~mW}$ $\mathrm{cm}^{-2}$ ) are shown in Figure 3a, and the comprehensive photovoltaic parameters of $V_{\mathrm{oc}} J_{\mathrm{sc}} \mathrm{FF}$, and PCE are converged in Table 1. The PTB7-Th:DICTF-C10 devices showed a maximum power conversion efficiency (PCE) of $6.93 \%$ with a $V_{\text {oc }}$ of $0.865 \mathrm{~V}$, a $J_{\text {sc }}$ of $16.35 \mathrm{~mA} \mathrm{~cm}{ }^{-2}$, and an $\mathrm{FF}$ of 0.50 whereas the PTB7-Th:DICTF-TEG devices displayed a maximum PCE of only $3.09 \%$ with a lower $V_{\text {oc }}$ of $0.794 \mathrm{~V}$, a much lower $J_{\text {sc }}$ of $10.31 \mathrm{~mA} \mathrm{~cm}{ }^{-2}$, and a lower FF of 0.38 . It should be noted that the photovoltaic performance of DICTF-
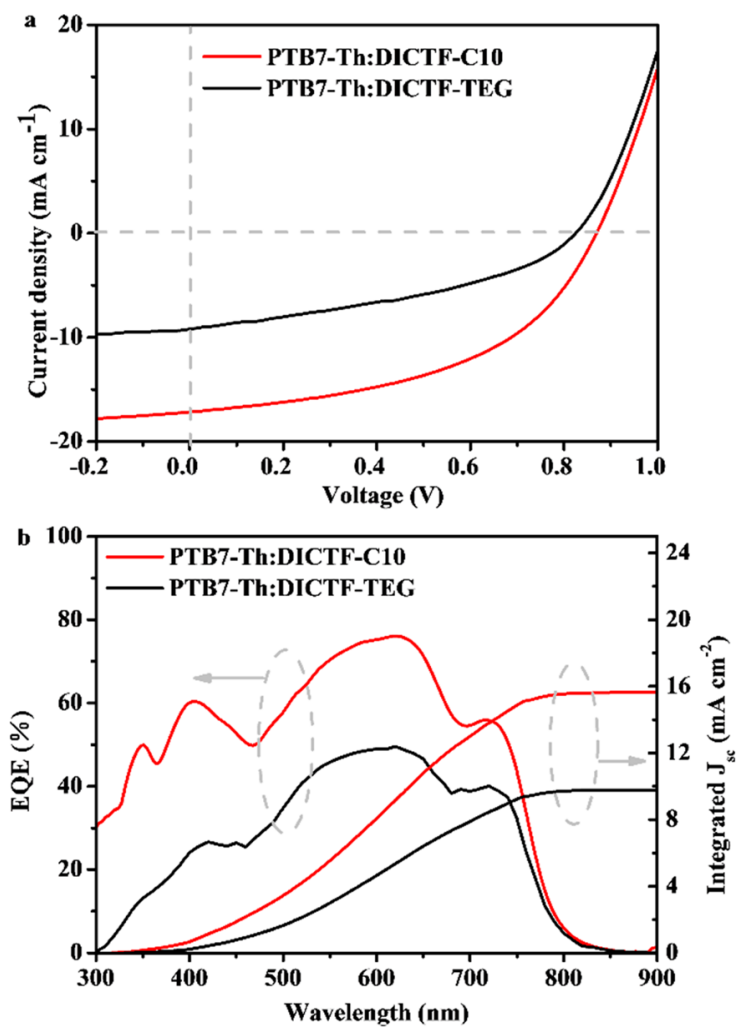

Figure 3. (a) Typical current density-voltage $(J-V)$ characteristics of optimized BHJ devices with the blend of PTB7-Th:acceptor (DICTFC10 and DICTF-TEG) under AM $1.5 \mathrm{G}$ illumination $\left(100 \mathrm{~mW} \mathrm{~cm}^{-2}\right)$ and (b) corresponding EQE spectra and integrated $J_{\mathrm{sc}}$ curves.

C10 is comparable to the reported DICTF with octyl side chains when blended with PTB7-Th, indicating the objectivity of device performance characterizations in this work. ${ }^{39}$ The $V_{\mathrm{oc}}$ of the DICTF-C10-based device is $0.07 \mathrm{~V}$ higher than that of the DICTF-TEG-based one due to its slightly higher LUMO energy level. Furthermore, it is worth noting that the $J_{\mathrm{sc}}$ and the FF were dramatically decreased when TEG chains were introduced.

The external quantum efficiency (EQE) spectra of the optimized PTB7-Th:DICTF-C10 and PTB7-Th:DICTF-TEG devices were measured to verify the $J_{\mathrm{sc}}$ values obtained (Figure $3 b)$. A significantly higher external quantum efficiency with the maximum value approaching to $70 \%$ can be found in the absorption range for the PTB7-Th:DICTF-C10 device in comparison with that of the PTB7-Th:DICTF-TEG blend with the maximum EQE of only 50\%. This results of EQE spectra suggest that there exists inefficient photoelectron conversion process within the device of PTB7-Th:DICTF-TEG. For both devices, the integral current density values deduced from EQE spectra (15.64 mA cm${ }^{-2}$ for PTB7-Th:DICTF-C10 and 9.78 $\mathrm{mA} \mathrm{cm}{ }^{-2}$ for PTB7-Th:DICTF-TEG, respectively) matched well with those obtained from the $J-V$ measurements under AM 1.5G irradiation. Given the fact that the $\mathrm{BHJ}$ blend of PTB7-Th:DICTF-TEG only exhibits a little bit weaker absorption in the range from 500 to $620 \mathrm{~nm}$ (Figure S6) compared with that of PTB7-Th:DICTF-C10 with similar film thickness, the poor EQE values of the PTB7-Th:DICTF-TEG device in the whole absorption range could most likely be ascribed to less efficient charge carrier generation, transportation, and collection when TEG chains were introduced. 
Table 1. Maximum Photovoltaic Performance of BHJ PSCs with PTB7-Th:DICTF-C10 and PTB7-Th:DICTF-TEG Blends ${ }^{a}$

\begin{tabular}{ccccc}
\hline BHJ (D:A = 2:3) & $V_{\mathrm{oc}}(\mathrm{V})$ & $J_{\mathrm{sc}}\left(\mathrm{mA} \mathrm{cm}^{-2}\right)$ & FF & PCE $(\%)$ \\
\hline PTB7-Th:DICTF-C10 & $0.865(0.861 \pm 0.006)$ & $16.35(16.15 \pm 0.28)$ & $0.50(0.49 \pm 0.90)$ & $6.93(6.86 \pm 0.16)$ \\
PTB7-Th:DICTF-TEG & $0.794(0.787 \pm 0.009)$ & $10.31(10.11 \pm 0.32)$ & $0.38(0.37 \pm 0.80)$ & $3.09(2.98 \pm 0.13)$
\end{tabular}

${ }^{a_{T}}$ The average values and standard deviations are shown in the parentheses determined from 15 active devices.
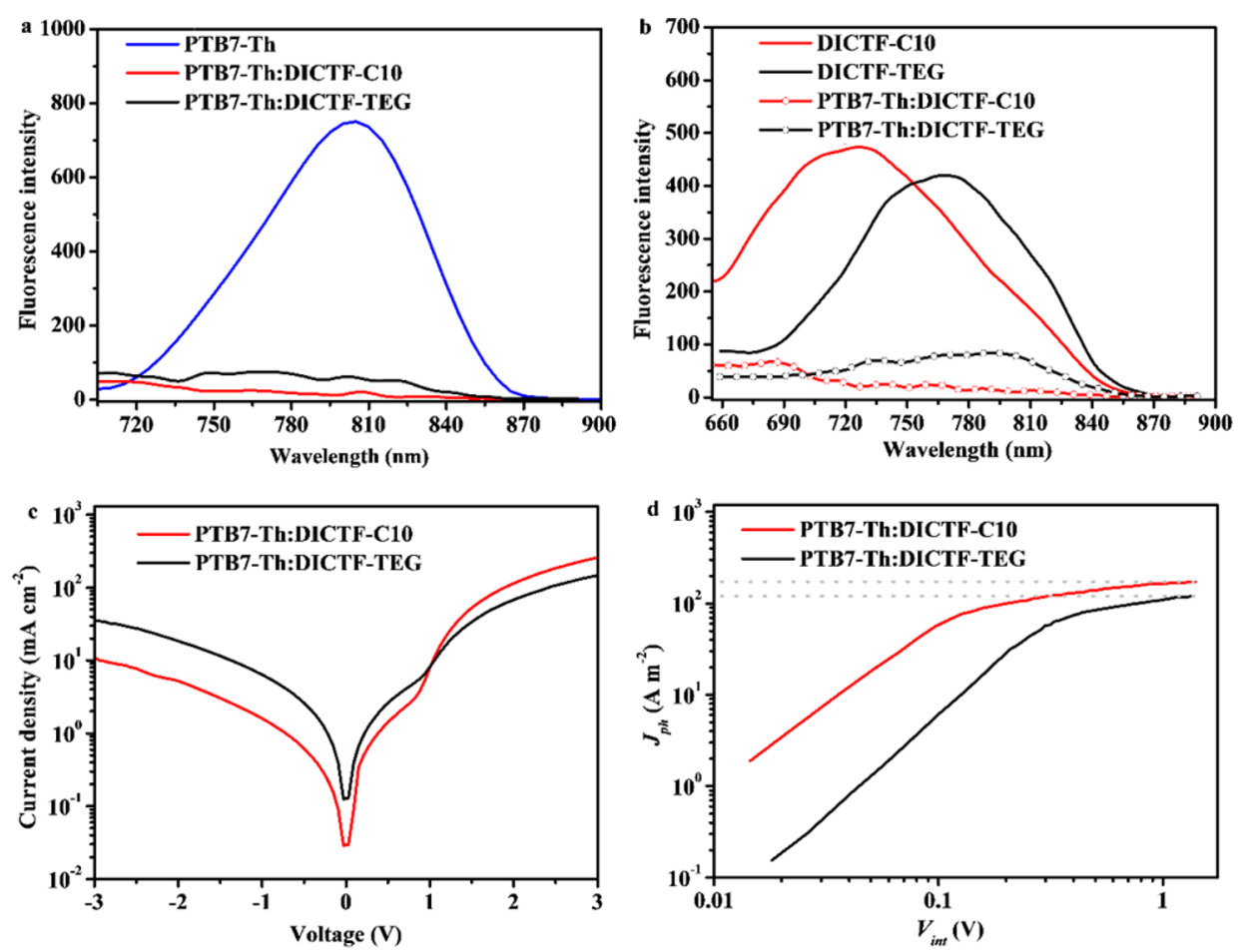

Figure 4. (a) Fluorescence spectra of the pure PTB7-Th film and the BHJ blend films with the two acceptors of DICTF-C10 and DICTF-TEG (excited at $688 \mathrm{~nm}$ ), (b) fluorescence spectra of the pure films of DICTF-C10 (excited at $645 \mathrm{~nm}$ ) and DICTF-TEG (excited at $650 \mathrm{~nm}$ ) and their corresponding BHJ blends with PTB7-Th, (c) $J-V$ characteristics of the optimized BHJ devices with the blend of PTB7-Th:acceptor swept from -3 $\mathrm{V}$ to $+3 \mathrm{~V}$ in the dark, and (d) $J_{\mathrm{ph}}$ versus effective voltage curves of the optimized BHJ devices with the two acceptors under AM 1.5G illumination.

3.5. Charge Generation, Transport, and Recombination. To investigate the exciton generation and dissociation behavior in the $\mathrm{BHJ}$ blends with the two acceptors, the fluorescence (FL) spectra of the films of the pure donor of PTB7-Th, the acceptors of DICTF-C10 and DICTF-TEG, and their corresponding optimized $\mathrm{BHJ}$ films were measured as shown in Figures 4a and 4b. The excitation wavelength of 688 $\mathrm{nm}$ was chosen for PTB7-Th while $645 \mathrm{~nm}$ for DICTF-C10 and $650 \mathrm{~nm}$ for DICTF-TEG according to their absorption spectra. FL of the $\mathrm{BHJ}$ blends were recorded by exciting both the donor of PTB7-Th and the acceptor of DICTF-C10 or DICTF-TEG. As indicated in Figure $4 \mathrm{a}$ in which the FL spectrum was detected by exciting the polymer donor, the FL of PTB7-Th is largely quenched by the acceptor ( 95\%) in the PTB7-Th:DICTF-C10 blend whereas only $\sim 86 \%$ in the PTB7Th:DICTF-TEG blend. When the FL spectrum was detected by exciting the acceptors respectively (Figure $4 \mathrm{~b}$ ), the FL of DICTF-C10 was quenched by PTB7-Th around $\sim 91 \%$ while only $\sim 77 \%$ in the PTB7-Th:DICTF-TEG blend. The results confirm the light-harvesting contribution from both the donor and the acceptors within the $\mathrm{BHJ}$ blends and indicate that the exciton generation and dissociation are more efficient in the case of the PTB7-Th:DICTF-C10 BHJ blend.

Prior to experimentally determining the maximum photoinduced charge carrier generation rate $\left(G_{\max }\right)$ in both devices with the two acceptors, the $J-V$ characteristics of both the optimized devices in the dark were measured and are presented in Figure 4c. There is serious leakage current at the negative bias in the device with the acceptor of DICTF-TEG, whereas such a significant leakage current is not observed at negative voltages as high as $-3 \mathrm{~V}$ for the PTB7-Th:DICTF-TEG blend. The diode leakage current is increased about 3-fold at $-3 \mathrm{~V}$ when the alkyl chains were replaced by the TEG chains. Figure $4 \mathrm{~d}$ reveals the photocurrent density $\left(J_{\mathrm{ph}}\right)$ versus the internal voltage $\left(V_{\text {int }}\right)$ of the optimized $\mathrm{BHJ}$ devices with the two acceptors under AM 1.5G illumination. For both devices, $J_{\mathrm{ph}}$ increases in proportion to the voltage at low $V_{\text {int }}$ but tends to saturate (namely, the saturated photocurrent, $J_{\text {ph,sat }}$ ) at high $V_{\text {int }}$ over $1 \mathrm{~V}$. The $J_{\mathrm{ph} \text {,sat }}$ value is determined to be $172.13 \mathrm{~A} \mathrm{~m}^{-2}$ for the PTB7-Th:DICTF-C10 device and $120.01 \mathrm{~A} \mathrm{~m}^{-2}$ for the PTB7-Th:DICTF-TEG device. The $G_{\max }$ is calculated to be $1.51 \times 10^{28} \mathrm{~m}^{-3} \mathrm{~s}^{-1}$ for the PTB7-Th:DICTF-C10 device with nearly a $36 \%$ increase compared to $1.12 \times 10^{28} \mathrm{~m}^{-3} \mathrm{~s}^{-1}$ of the PTB7-Th:DICTF-TEG device, according to $G_{\max }=J_{\text {ph,sat }} /(q L)$ where $q$ is the elementary charge and $L$ is the film thickness of the BHJ films. ${ }^{40}$ Obviously, the PTB7-Th:DICTF-C10 device offers more photogenerated excitons and dissociated charge carriers, which is consistent with the results of fluorescence measurements. The charge collection probability $\left(P_{\mathcal{c}}\right.$ equals to $\left.J_{\mathrm{ph}} / J_{\mathrm{ph}, \mathrm{sat}}\right)$ of the devices at the short circuit condition decreases from $95.0 \%$ to $85.9 \%$ by switching the alkyl chains to the TEG chains. 

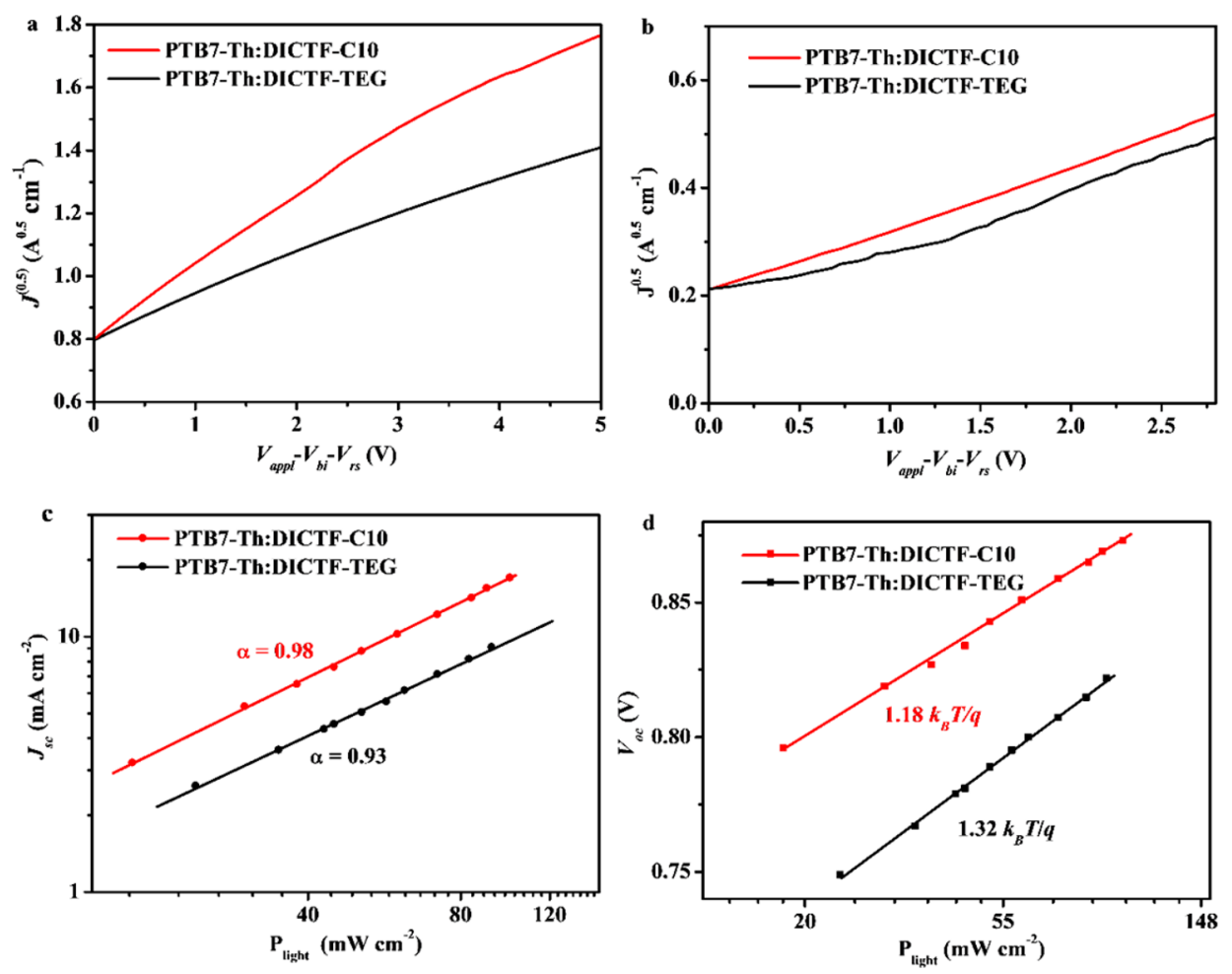

Figure 5. $J^{0.5}$ vs $V\left(V=V_{\text {appl }}-V_{\mathrm{bi}}-V_{\mathrm{rs}}\right)$ plots for (a) hole-only and (b) electron-only devices of PTB7-Th:acceptor (DICTF-C10 or DICTF-TEG). (c) Measured $J_{\text {sc }}$ of the optimized BHJ devices with DICTF-C10 and DICTF-TEG against $P_{\text {light }}$ on a logarithmic scale and (d) light intensity dependence of measured $V_{\text {oc }}$ of the optimized BHJ devices with DICTF-C10 and DICTF-TEG.

The charge transport property was then investigated by measuring the hole $\left(\mu_{\mathrm{h}}\right)$ and the electron $\left(\mu_{\mathrm{e}}\right)$ mobility from space-charge limited current (SCLC) model by the use of holeand electron-only devices with the configuration of ITO/ PEDOT:PSS/PTB7-Th:acceptor/ $\mathrm{MoO}_{3} / \mathrm{Ag}$ and ITO/ZnO/ PTB7-Th:acceptor/Ca/Al, respectively. The $J^{0.5}$ vs $V$ (the voltage drop across the device, $V=V_{\text {app }}-V_{\text {rs }}-V_{\text {bit }}$, where $V_{\text {app }}$ is the applied voltage, $V_{\mathrm{rs}}$ is from contact and series resistance, and $V_{\text {bit }}$ is from built-in voltage) plots for the hole- and electriconly devices of PTB7-Th:DICTF-C10 and PTB7-Th:DICTFTEG BHJ blends are shown in Figure $5 \mathrm{a}$ and $5 \mathrm{~b}$, respectively. The PTB7-Th:DICTF-C10 BHJ blend offers a $\mu_{\mathrm{h}}$ value of 4.6 $\times 10^{-5} \mathrm{~cm}^{2} \mathrm{~V}^{-1} \mathrm{~s}^{-1}$ and a $\mu_{\mathrm{e}}$ value of $2.3 \times 10^{-5} \mathrm{~cm}^{2} \mathrm{~V}^{-1} \mathrm{~s}^{-1}$ with the $\mu_{\mathrm{h}} / \mu_{\mathrm{e}}$ value of $2: 1$, whereas the PTB7-Th:DICTFTEG BHJ blend offers a lower $\mu_{\mathrm{h}}$ value of $1.6 \times 10^{-5} \mathrm{~cm}^{2} \mathrm{~V}^{-1}$ $\mathrm{s}^{-1}$ and a much decreased $\mu_{\mathrm{e}}$ value of $0.4 \times 10^{-5} \mathrm{~cm}^{2} \mathrm{~V}^{-1} \mathrm{~s}^{-1}$ with the $\mu_{\mathrm{h}} / \mu_{\mathrm{e}}$ value of $4: 1$. Briefly, not only the charge carrier mobility is trimmed but also the transport balance between the holes and the electrons is deteriorated; it is no wonder that the much lower $J_{\mathrm{sc}}$ and FF were observed when the TEG chains were introduced.

We further investigated the charge recombination behaviors by probing the incident light intensity $\left(P_{\text {light }}\right)$ dependent $J-V$ characteristics of the $\mathrm{BHJ}$ devices with the two acceptors. Fitting the logarithmic plots of $J_{s c}$ as a function of $P_{\text {light }}$ according to $J_{\mathrm{sc}} \propto P_{\text {light }}{ }^{\alpha}$ in Figure 5c yields a larger $\alpha$ of 0.98 in the PTB7-Th:DICTF-C10 device than that of 0.93 in the PTB7-Th:DICTF-TEG device, indicating more bimolecular recombination loss in the latter device at the closed circuit condition. On the other hand, as shown in Figure 5d, treating $V_{\text {oc }}$ as a function of $P_{\text {light }}$ according to $V_{\text {oc }} \propto\left(n k_{\mathrm{B}} T\right) / q \ln \left(P_{\text {light }}\right)$ ( $k_{\mathrm{B}}$ is the Boltzmann constant, $T$ is the temperature in kelvin, and $q$ is the elementary charge) affords a $n$ value of 1.18 in the device with DICTF-C10 and a larger $n$ value of 1.32 in the device with DICTF-TEG, indicative of an increased trapassisted recombination in the latter device at the open circuit condition. Such increased charge recombination would lead to less charge carriers surviving the transport process and finally being extracted, resulting in the lower $J_{\text {sc }}$ and FF in the PTB7Th:DICTF-TEG device.

3.6. Morphology Study. Considering the distinction on solid state ordering of the two acceptors and their distinctive photovoltaic properties, we speculate that forming the $\mathrm{BHJ}$ blends of the two acceptors with the PTB7-Th donor probably result in apparent morphological differences, which can significantly influence the exciton dissociation and charge transport. Depicted in Figure 6 is the in-plane and out-of-plane GIWAXS profiles of the BHJ films of PTB7-Th:DICTF-C10

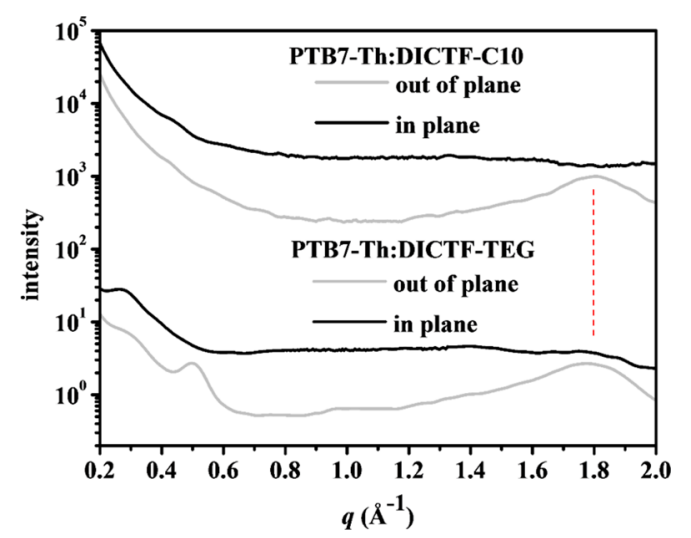

Figure 6. In-plane and out-of-plane GIWAXS profiles of the BHJ films of PTB7-Th:DICTF-C10 and PTB7-Th:DICTF-TEG. 
and PTB7-Th:DICTF-TEG. For the PTB7-Th:DICTF-C10 blend, only a broad diffraction peak at $\sim 1.8 \AA^{-1}$ in the out-ofplane direction can be obviously observed, which most likely consists of the superposed (010) diffraction peaks of PTB7-Th and DICTF-C10. Such (010) reflections along the out-of-plane direction suggest that both PTB7-Th and DICTF-C10 in the $\mathrm{BHJ}$ blend preferably take face-on orientation on the $\mathrm{ZnO}$ layer, although the corresponding (100) reflections determined by the interchain distance between alkyl side chains are not obviously observed along the in-plane direction. When mixing DICTF-TEG with the polymer donor of PTB7-Th, weak (100) reflections at $\sim 0.28 \AA^{-1}$ along both the in-plane and out-ofplane directions can be observed, which can be most likely ascribed to the interchain stacking between the alkyl side chains of PTB7-Th in considering together the structure feature of the neat film of DICTF-TEG as indicated in Figure $2 .{ }^{40}$ In addition, a (200) reflection at $q=0.50 \AA^{-1}$ assigned to DICTF-TEG can still be observed along the out-of-plane direction. Importantly, a much broader reflection at $\sim 1.8 \AA^{-1}$ in the out-of-plane direction is observed, which could be discernibly resolved as two reflections roughly at $\sim 1.78 \AA^{-1}$ (corresponding to a $\pi-\pi$ stacking distance of $3.53 \AA$ ) and $\sim 1.83 \AA^{-1}$ (with a $\pi-\pi$ stacking distance of $3.43 \AA$ ) corresponding to the (010) reflections of PTB7-Th and DICTF-TEG. Briefly, in the PTB7Th:DICTF-TEG BHJ blend, although most of the crystals of PTB7-Th and DICTF-TEG take face-on orientation, a part of edge-on orientation still exists, which may contribute to the lower $\mu_{\mathrm{h}}$ of PTB7-Th and the decreased $\mu_{\mathrm{e}}$ of DICTF-TEG in the $\mathrm{BHJ}$ blend. ${ }^{40}$ It need to be noted here that the $\pi-\pi$ stacking distance of DICTF-TEG remains decreased as well in comparison with that of DICTF-C10 in the BHJ blend.

We then probed the surface morphological feature of the $\mathrm{BHJ}$ blends by the use of atomic force microscopy (AFM). As shown in Figure 7, the optimized BHJ films give a root-meansquare (rms) roughness of $2.55 \mathrm{~nm}$ for PTB7-Th:DICTF-C10 whereas of $5.42 \mathrm{~nm}$ for PTB7-Th:DICTF-TEG. Discernible

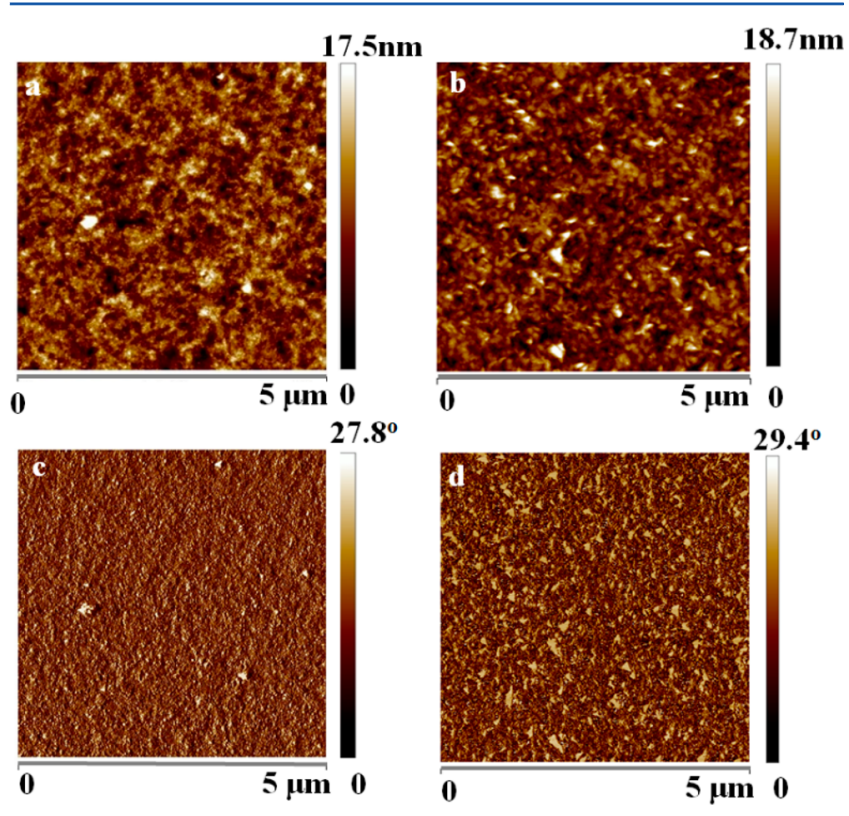

Figure 7. Tapping mode AFM height images $(5 \times 5 \mu \mathrm{m})$ of the optimized BHJ films of PTB7-Th:DICTF-C10 (a) and PTB7Th:DICTF-TEG (b) and corresponding phase images of the blend of PTB7-Th:DICTF-C10 (c) and PTB7-Th:DICTF-TEG (d). fiber-like structures can be observed with delicate phaseseparated domains of $\sim 15 \mathrm{~nm}$ for the PTB7-Th:DICTF-C10 film. Nevertheless, rougher surface with coarse structures in the PTB7-Th:DICTF-TEG film leads to larger and featureless phase-separated domains $(\sim 30 \mathrm{~nm})$, which possibly resulted from the relatively inferior miscibility of DICTF-TEG with PTB7-Th in considering the amount of the acceptor with TEG side chains is 1.5 equiv to that of the polymer donor with alkyl side chains in the BHJ blend. ${ }^{41}$ As observed from the GIWAXS profiles of the BHJ films in Figure 6, both PTB7-Th and DICTF-TEG in the BHJ film present better crystallinity, indicating stronger tendency of the two active components to aggregate separately instead of mixing with each other evenly. Close to the theoretical exciton diffusion length in organic conjugated materials $(\sim 10 \mathrm{~nm})$, the appropriate phase separation domains of the PTB7-Th:DICTF-C10 film could reduce the unfavorable charge recombination caused by too large one observed for the film of PTB7-Th:DICTF-TEG as disclosed above. This reasonably explains the improved generation and dissociation efficiency of excitons and the much improved $J_{\text {sc }}$ FF, and therefore PCE of the PTB7Th:DICTF-C10 device in spite of the fact that the TEG chains do improve the $\pi-\pi$ stacking interaction of DICTF-TEG.

\section{CONCLUSIONS}

In summary, the device performance of polymer solar cells based on non-fullerene acceptors with TEG and alkyl side chains was investigated. The effects of the two types of side chains on the photovoltaic properties of easily accessible fluorene-based non-fullerene acceptors were disclosed. It was found that replacing alkyl side chains with TEG chains can improve the $\pi-\pi$ stacking interaction of conjugated backbones of the acceptors in solid state as expected. When mixing the alkylated acceptor with the polymer donor of PTB7-Th, the preferred face-on orientation of the crystals of the two components within the $\mathrm{BHJ}$ film was observed. However, the introduction of TEG side chains led to inferior miscibility between the donor and acceptor component and resulted in a dominant face-on orientation together with a partial edge-on orientation of the crystals of the two components in the $\mathrm{BHJ}$ film. Such unfavorable film morphology structure of the active blend led to the deteriorated device performance, which is completely different from reported results that introducing TEG chains into conjugated polymer donors can improve device performance with optimized molecular packing in polymer:fullerene blends. This comparative study demonstrates that empirical side chain engineering by the introduction of OEG chains into conjugated backbones does not always straightly translate into performance enhancement in the resulting $\mathrm{BHJ}$ devices. The information evolved from this comparative study allows the establishment of guidance on molecular engineering of non-fullerene molecular acceptors to obtain high performance PSCs.

\section{ASSOCIATED CONTENT}

\section{S Supporting Information}

The Supporting Information is available free of charge on the ACS Publications website at DOI: 10.1021/acsaem.8b00012.

General information on materials, NMR and highresolution MALDI-TOF mass spectra of new compounds, TGA, cyclic voltammogram curves, the UPS spectra of the thin films, and the powdery XRD profiles 
of the acceptors, the energy level diagrams of the electronic martials with the BHJ PSCs in inverted architecture, the absorption spectra of the optimized $\mathrm{BHJ}$ films, and GIWAXS patterns of films of pristine acceptors and the BHJ blends (PDF)

\section{AUTHOR INFORMATION}

\section{Corresponding Authors}

*E-mail: shengqiang@whut.edu.cn (S.X.).

*E-mail: wyou@unc.edu (W.Y.).

ORCID

Shengqiang Xiao: 0000-0001-7644-8491

Wei You: 0000-0003-0354-1948

\section{Notes}

The authors declare no competing financial interest.

\section{ACKNOWLEDGMENTS}

This research is financially supported by National Natural Science Foundation of China (21673170) and State Key Laboratory of Advanced Technology for Materials Synthesis and Processing (2017-KF-9). The authors greatly thank Dr. Xinhui Lu from Department of Physics, Chinese University of Hong Kong, Hong Kong, P. R. China, for providing the assistance on GIWAXS measurement and data processing.

\section{REFERENCES}

(1) Kang, H.; Kim, G.; Kim, J.; Kwon, S.; Kim, H.; Lee, K. BulkHeterojunction Organic Solar Cells: Five Core Technologies for Their Commercialization. Adv. Mater. 2016, 28, 7821-7861.

(2) Yin, Z.; Wei, J.; Zheng, Q. Interfacial Materials for Organic Solar Cells: Recent Advances and Perspectives. Adv. Sci. 2016, 3, 1500362.

(3) Lu, L.; Zheng, T.; Wu, Q.; Schneider, A. M.; Zhao, D.; Yu, L. Recent Advances in Bulk Heterojunction Polymer Solar Cells. Chem. Rev. 2015, 115, 12666-12731.

(4) Zhang, K.; Hu, Z.; Sun, C.; Wu, Z.; Huang, F.; Cao, Y. Toward Solution-Processed High-Performance Polymer Solar Cells: from Material Design to Device Engineering. Chem. Mater. 2017, 29, 141-148.

(5) Yu, G.; Gao, J.; Hummelen, J. C.; Wudl, F.; Heeger, A. J. Polymer Photovoltaic Cells: Enhanced Efficiencies via a Network of Internal Donor-Acceptor Heterojunctions. Science 1995, 270, 1789-1791.

(6) Matsuo, Y. Fullerene Derivatives as Electron Acceptors in Polymer Solar Cells. In Polymer Photovoltaics: Materials, Physics, and Device Engineering; Huang, F., Yip, H.-L., Cao, Y., Eds.; Polymer Chemistry Series; The Royal Society of Chemistry: 2016; pp 78-100.

(7) Yan, H.; McNeill, C. R.; Mu, C. Polymer Acceptors for AllPolymer Solar Cells. In Polymer Photovoltaics: Materials, Physics, and Device Engineering; Huang, F., Yip, H.-L., Cao, Y., Eds.; Polymer Chemistry Series; The Royal Society of Chemistry: 2016; pp 101126.

(8) Kang, H.; Lee, W.; Oh, J.; Kim, T.; Lee, C.; Kim, B. J. From Fullerene-Polymer to All-Polymer Solar Cells: The Importance of Molecular Packing, Orientation, and Morphology Control. Acc. Chem. Res. 2016, 49, 2424-2434.

(9) Chen, W.; Yang, X.; Long, G.; Wan, X.; Chen, Y.; Zhang, Q. A Perylene Diimide (PDI)-based Small Molecule with Tetrahedral Configuration as a Non-fullerene Acceptor for Organic Solar Cells. J. Mater. Chem. C 2015, 3, 4698-4705.

(10) Sun, H.; Song, X.; Xie, J.; Sun, P.; Gu, P.; Liu, C.; Chen, F.; Zhang, Q.; Chen, Z.-K.; Huang, W. PDI Derivative through FineTuning the Molecular Structure for Fullerene-Free Organic Solar Cells. ACS Appl. Mater. Interfaces 2017, 9, 29924-29931.

(11) Chen, W.; Zhang, Q. Recent Progress in Non-fullerene Small Molecule Acceptors in Organic Solar Cells (OSCs). J. Mater. Chem. C 2017, 5, 1275-1302.
(12) Li, W.; Yao, H.; Zhang, H.; Li, S.; Hou, J. Potential of Nonfullerene Small Molecules with High Photovoltaic Performance. Chem. - Asian J. 2017, 12, 2160-2171.

(13) Liang, N.; Jiang, W.; Hou, J.; Wang, Z. New Developments in Non-fullerene Small Molecule Acceptors for Polymer Solar Cells. Mater. Chem. Front. 2017, 1, 1291-1303.

(14) Dai, S.-X.; Zhan, X.-W. Fused-Ring Electron Acceptors for Organic Solar Cells. Acta Polym. Sin. 2017, 11, 1706-1714.

(15) Zhao, J.; Li, Y.; Yang, G.; Jiang, K.; Lin, H.; Ade, H.; Ma, W.; Yan, H. Efficient Organic Solar Cells Processed from Hydrocarbon Solvents. Nat. Energy 2016, 1, 15027.

(16) Zhao, W.; Li, S.; Yao, H.; Zhang, S.; Zhang, Y.; Yang, B.; Hou, J. Molecular Optimization Enables over 13\% Efficiency in Organic Solar Cells. J. Am. Chem. Soc. 2017, 139, 7148-7151.

(17) Fan, B.; Ying, L.; Wang, Z.; He, B.; Jiang, X.-F.; Huang, F.; Cao, Y. Optimisation of Processing Solvent and Molecular Weight for the Production of Green-solvent-processed All-polymer Solar Cells with a Power Conversion Efficiency over 9\%. Energy Environ. Sci. 2017, 10, $1243-1251$

(18) Li, Z.; Xu, X.; Zhang, W.; Meng, X.; Genene, Z.; Ma, W.; Mammo, W.; Yartsev, A.; Andersson, M. R.; Janssen, R. A. J.; Wang, E. 9.0\% Power Conversion Efficiency from Ternary All-polymer Solar Cells. Energy Environ. Sci. 2017, 10, 2212-2221.

(19) Bazan, G. C. Over 9\% Efficiency Achieved for All-polymer Solar Cells Processed by a Green Solvent. Sci. China: Chem. 2017, 60, $1109-1110$

(20) Xiao, Z.; Jia, X.; Ding, L. Ternary Organic Solar Cells Offer 14\% Power Conversion Efficiency. Sci. Bull. 2017, 62, 1562-1564.

(21) Hildner, R.; Köhler, A.; Müller-Buschbaum, P.; Panzer, F.; Thelakkat, M. $\pi$-Conjugated Donor Polymers: Structure Formation and Morphology in Solution, Bulk and Photovoltaic Blends. Adv. Energy Mater. 2017, 7, 1700314.

(22) Xiao, S.; Zhang, Q.; You, W. Molecular Engineering of Conjugated Polymers for Solar Cells: An Updated Report. Adv. Mater. 2017, 29, 1601391.

(23) Su, Y.-W.; Lin, Y.-C.; Wei, K.-H. Evolving Molecular Architectures of Donor-acceptor Conjugated Polymers for Photovoltaic Applications: from One-dimensional to Branched to TwoDimensional Structures. J. Mater. Chem. A 2017, 5, 24051-24075.

(24) Yang, S.-F.; Liu, Z.-T.; Cai, Z.-X.; Dyson, M. J.; Stingelin, N.; Chen, W.; Ju, H.-J.; Zhang, G.-X.; Zhang, D.-Q. DiketopyrrolopyrroleBased Conjugated Polymer Entailing Triethylene Glycols as Side Chains with High Thin-Film Charge Mobility without Post-Treatments. Adv. Sci. 2017, 4, 1700048.

(25) Ma, Y.; Kang, Z.; Zheng, Q. Recent Advances in Wide Bandgap Semiconducting Polymers for Polymer Solar Cells. J. Mater. Chem. A 2017, 5, 1860-1872.

(26) Cai, Y.; Huo, L.; Sun, Y. Recent Advances in Wide-Bandgap Photovoltaic Polymers. Adv. Mater. 2017, 29, 1605437.

(27) Liu, C.; Wang, K.; Gong, X.; Heeger, A. J. Low Bandgap Semiconducting Polymers for Polymeric Photovoltaics. Chem. Soc. Rev. 2016, 45, 4825-4846.

(28) Wu, J.-S.; Cheng, S.-W.; Cheng, Y.-J.; Hsu, C.-S. Donor-acceptor Conjugated Polymers Based on Multifused Ladder-type Arenes for Organic Solar Cells. Chem. Soc. Rev. 2015, 44, 1113-1154.

(29) Yang, M.; Lau, T.-K.; Xiao, S.; Gao, J.; Wang, W.; Lu, X.; Zhang, S.; Wu, J.; Zhan, C.; You, W. A Ladder-type Heteroheptacene $12 \mathrm{H}-$ Dithieno $\left[2^{\prime}, 3^{\prime}: 4,5\right]$ thieno $\left[3,2-\mathrm{b}: 2^{\prime}, 3^{\prime}-\mathrm{h}\right]$ fluorene Based D-A Copolymer with Strong Intermolecular Interactions toward Efficient Polymer Solar Cells. ACS Appl. Mater. Interfaces 2017, 9, 35159-35168.

(30) Lei, T.; Wang, J.-Y.; Pei, J. Roles of Flexible Chains in Organic Semiconducting Materials. Chem. Mater. 2014, 26, 594-603.

(31) Mei, J.; Bao, Z. Side Chain Engineering in Solution-Processable Conjugated Polymers. Chem. Mater. 2014, 26, 604-615.

(32) Zhang, Z.-G.; Li, Y. Side-chain Engineering of High-efficiency Conjugated Polymer Photovoltaic Materials. Sci. China: Chem. 2015, 58, 192-209.

(33) Sengwa, R. J. Solvent Effects on Microwave Dielectric Relaxation in Poly(ethylene glycols). Polym. Int. 1998, 45, 43-46. 
(34) Torabi, S.; Jahani, F.; Van Severen, I.; Kanimozhi, C.; Patil, S.; Havenith, R. W. A.; Chiechi, R. C.; Lutsen, L.; Vanderzande, D. J. M.; Cleij, T. J.; Hummelen, J. C.; Koster, L. J. A. Strategy for Enhancing the Dielectric Constant of Organic Semiconductors Without Sacrificing Charge Carrier Mobility and Solubility. Adv. Funct. Mater. 2015, 25, 150-157.

(35) Hoang, Q. V.; Song, C. E.; Moon, S.-J.; Lee, S. K.; Lee, J.-C.; Kim, B. J.; Shin, W. S. Asymmetric Electron-Donating 4-Alkyl-8alkoxybenzo[1,2-b:4,5- $\left.\mathrm{b}^{\prime}\right]$ dithiophene Unit for Use in High-Efficiency Bulk Heterojunction Polymer Solar Cells. Macromolecules 2015, 48, 3918-3927.

(36) Chen, Y.; Zhang, S.; Wu, Y.; Hou, J. Molecular Design and Morphology Control Towards Efficient Polymer Solar Cells Processed Using Non-aromatic and Non-chlorinated Solvents. Adv. Mater. 2014, 26, 2744-2749.

(37) Meng, B.; Song, H.; Chen, X.; Xie, Z.; Liu, J.; Wang, L. Replacing Alkyl with Oligo(ethylene glycol) as Side Chains of Conjugated Polymers for Close $\pi-\pi$ Stacking. Macromolecules 2015, 48, 4357-4363.

(38) Chen, X.; Zhang, Z.; Ding, Z.; Liu, J.; Wang, L. Diketopyrrolopyrrole-based Conjugated Polymers Bearing Branched Oligo(Ethylene Glycol) Side Chains for Photovoltaic Devices. Angew. Chem., Int. Ed. 2016, 55, 10376-10380.

(39) Li, M.; Liu, Y.; Ni, W.; Liu, F.; Feng, H.; Zhang, Y.; Liu, T.; Zhang, H.; Wan, X.; Kan, B.; Zhang, Q.; Russell, T. P.; Chen, Y. A Simple Small Molecule as an Acceptor for Fullerene-free Organic Solar Cells with Efficiency near 8\%. J. Mater. Chem. A 2016, 4, 1040910413.

(40) Gao, J.; Wang, W.; Zhang, S.; Xiao, S.; Zhan, C.; Yang, M.; Lu, X.; You, W. Distinction between PTB7-Th Samples Prepared from $\mathrm{Pd}\left(\mathrm{PPh}_{3}\right)_{4}$ and $\mathrm{Pd}_{2}(\mathrm{dba})_{3} / \mathrm{P}(o-\text { tol })_{3}$ Catalysed Stille Coupling Polymerization and the Resultant Photovoltaic Performance. J. Mater. Chem. A 2018, 6, 179-188.

(41) Yin, J.; Zhou, Y.; Lei, T.; Pei, J. A Butterfly-Shaped Amphiphilic Molecule: Solution-Transferable and Free-Standing Bilayer Films for Organic Transistors. Angew. Chem., Int. Ed. 2011, 50, 6320-6323. 